\title{
Incidentalomas during pregnancy
}

Dharshini Karuppiah $^{1}$, Dilakkumar Sundaralingam ${ }^{2}$, Anura Pallewattha ${ }^{3}$, Saravanan Sitthambalam ${ }^{1}$

${ }^{1}$ Teaching Hospital Batticaloa

${ }^{2}$ Base Hospital Kalmunai

${ }^{3}$ National Hospital Sri Lanka

Correspondence email: kdharshinik@gmail.com

ORCHID ID: https://orcid.org/0000-0003-3546-8685

Copyright: This is an open-access article distributed under the terms of the Creative Commons Attribution License, which permits unrestricted use, distribution, and reproduction in any medium, provided the original author and source are credited (CC BY 4.0)

A 37 year old primi-parous female in her 21st week of gestation was referred with large right suprarenal mass found on routine ultrasound scan. Apart from occasional palpitation, she had no significant medical history. Her clinical examination was normal with the blood pressure of $110 / 70 \mathrm{mmHg}$ and pulse rate of 92 . Her maternal condition was stable.

What are the differential diagnoses?

Adrenal tumours identified during pregnancy is very rare. Phaeochromocytomas are the widely reported functioning adrenal tumours with a prevalence of 1 in 50,000 in full term pregnancies (1). Other functioning tumours include adrenal cortisol secreting adenomas and aldosterone secreting adenomas (2, 3). Other non-secretory tumours include adenoma, myelolipoma, lipoma, teratoma, angiomyolipoma and liposarcoma. ${ }^{(4)}$

\section{What are the further Investigations?}

Although she has no suggestive key signs and symptoms, exclusion of functioning adrenal tumour is crucial for maternal and foetal survival. Pregnancy causes many hormone levels to be elevated and lab analysis may be difficult to interpret. Exceptionally catecholamine level remain normal in pregnancy. 24 hour urinary free catecholamines has high accuracy. Diagnosing cortisol hypersecretion during pregnancy is difficult. Urinary-free cortisol and plasma cortisol levels are elevated at least three times compared to the non-pregnant state but diurnal rhythms are maintained. Dexamethazone suppression test is not accurate in the oestrogen excess state. Therefore assessing diurnal rhythms by serum cortisol measurements at 0800 and 2300 hours and 24-hour urine-free cortisol level in multiple samples and measuring ACTH levels have been suggested. (5)

This patient had normal $24 \mathrm{~h}$ urine metanephrines on 2 separate samples and her 8 am and $11 \mathrm{pm}$ serum cortisol levels were $275 \mathrm{nmol} / 1$ and $154 \mathrm{nmol} / 1$ respectively. Serum electrolytes and other biochemical parameters were within normal range.

What are the options for adrenal imaging during pregnancy?

Following ultrasonography, magnetic resonance imaging (MRI) is the preferred modality in pregnancy as it gives high quality images and avoid radiation exposure. CT and metaiodobenzylguanidine (MIBG) scans are contraindicated in pregnancy.

Figure 1: MRI abdomen showing large right supra-renal lesion and foetus inside the uterus
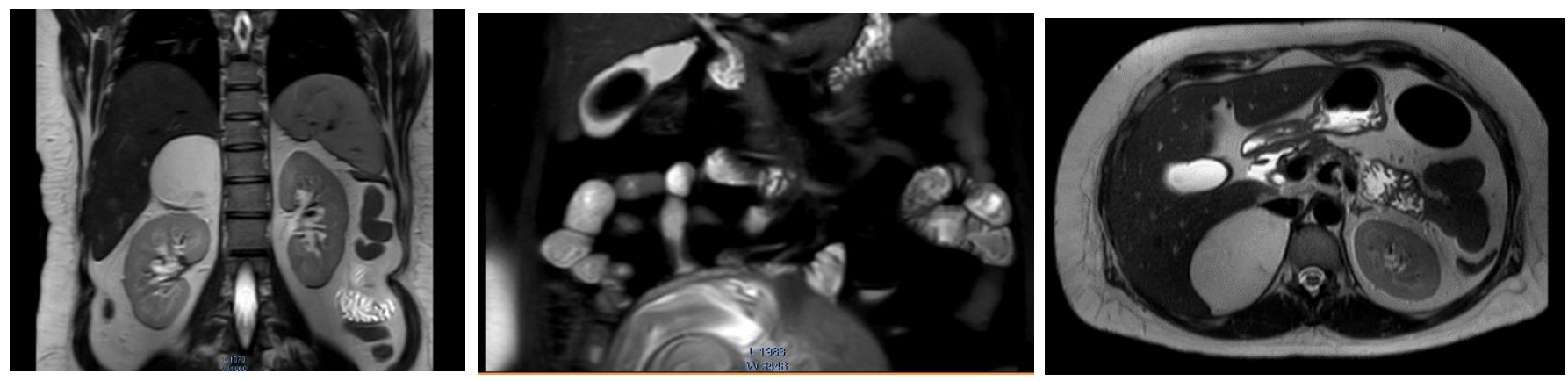


\section{What is the radiological diagnosis?}

There is a well-defined lesion in the right suprarenal region measuring $6.6 \times 5.5 \times 5.8 \mathrm{~cm}$. Hyperintense on T1 and T2w with complete fat suppression on $\mathrm{T} 1 \mathrm{w}$ image suggestive of adrenal myelolipoma.

\section{What are the operative strategy during pregnancy?}

Functioning adrenal tumours should be removed earlier, however it may vary depending on stage of pregnancy and type of tumour. Medical management and adrenalectomy in second trimester may be safer option. In-contrast, there is no consensus on management of non-functioning adrenal tumours in pregnancy, especially with regard to timing of surgery.
Adrenal myelolipomas are rare tumours, mostly nonsecretory and benign in nature; commonly reported after fifth decade of life. Very few cases reported during pregnancy. Management of adrenal myelolipoma should be considered on individual basis. Small lesions could be periodically monitored, but larger lesions warrant surgical resection to prevent spontaneous rupture and haemorrhage (6).

This patient is asymptomatic and managed conservatively. She underwent elective caesarean section at 37 weeks and delivered $3 \mathrm{~kg}$ healthy baby boy. Right adrenalectomy was planned 6 month post-partum.

\section{References}

1. Pace DE, Chiasson PM, Schlachta CM, Mamazza J, Cadeddu MO, Poulin EC. Minimally invasive adrenalectomy for pheochromocytoma during pregnancy. Surg Laparosc Endosc Percutan Tech. 2002; 12:122-125.

2. Okawa T, Asano K, Hashimoto T, Fujimori K,Yanagida K, Sato A. Diagnosis and management of primary aldosteronism in pregnancy: case report and review of the literature. Am J Perinatol. 2002; 19:31-36

3. Prebtani AP, Donat D, Ezzat S. Worrisome striae in pregnancy. Lancet. 2000; 355:1692

4. George T Griffing, Romesh Khardori. Adrenal incidentaloma. Medscape, updated March 2020.

5. M. Nicole Lamb, David R. Farley. Adrenal tumours and pregnancy

6. S. Daneshmand and M. L. Quek,. Adrenal myelolipoma: diagnosis and management, Journal of Urology, 2006; 3:71-74. 